\title{
Abordagens de gênero e sexualidade: um contraponto ao Escola Sem Partido
}

Gender and sexuality approaches:

a counterpoint to the Non-partisan School

\section{Abordajes de género y sexualidad: un contrapunto a la Escuela Sin Partido}

REGINA RODRIGUES COSTA*

Universidade Federal de Pernambuco- PE, Brasil.

AIDA MONTEIRO SILVA**

Universidade Federal de Pernambuco- PE, Brasil.

\begin{abstract}
RESUMO: Este artigo objetiva analisar a importância das abordagens de gênero nas escolas e os ataques do movimento/programa Escola sem Partido a esta temática. Faremos um recorte histórico, subsidiado por uma análise bibliográfica, a partir das discussões de gênero e sexualidade em Louro $(1997,2000)$, Britzman $(1996,2000)$ e estudos sobre o movimento Escola Sem Partido, em Moura (2016), Miguel (2016) e Penna (2017). Os resultados evidenciam que esse Programa deve ser combatido por não ter sustentação jurídica e por ferir princípios da Constituição brasileira na pluralidade de ideias e de pensamentos.

Palavras-chave: Gênero. Sexualidade. Educação. Escola Sem Partido.
\end{abstract}

\begin{abstract}
This article aims to analyze the importance of gender approaches in schools and the attacks of the Non-Partisan School movement / program to this theme. We will make a historical cut,
\end{abstract}

* Mestranda do Programa de Pós-Graduação em Direitos Humanos pela Universidade Federal de Pernambuco. É bacharel em Direito pela Universidade Federal da Paraíba, especialista em Direito Homoafetivo e de Gênero. Atua como Técnica-Administrativa no Instituto Federal da Paraíba. E-mail: $<$ re.rodrigues.araujo@gmail.com>.

** Doutora em Educação pela Universidade de São Paulo, atualmente é professora titular da Universidade Federal de Pernambuco, atuando nos cursos de licenciaturas, Programas de Pós-Graduação em Educação e Programa Interdisciplinar de Direitos Humanos. É Coordenadora da Red Latinoamericana y Caribeña de Educación en Derechos Humanos. E-mail:<trevoam@terra.com.br>. 
subsidized by a bibliographical analysis, from the discussions of gender and sexuality in Louro $(1997,2000)$, Britzman $(1996,2000)$ and studies on the Non-Partisan School movement, in Moura (2016), Miguel (2016) and Penna (2017). The results show that this program must be countered for not having legal support and for violating principles of the Brazilian Constitution in the plurality of ideas and thoughts.

Keywords: Gender. Sexuality. Education. Non-partisan School.

RESUMEN: Este artículo tiene como objetivo analizar la importancia de los enfoques de género en las escuelas y los ataques del movimiento/ programa Escuela sin Partido a este tema. Haremos un recorte histórico, subsidiado por un análisis bibliográfico, a partir de las discusiones sobre género y sexualidad en Louro (1997, 2000), Britzman (1996, 2000) y estudios sobre el movimiento Escuela sin Partido, en Moura (2016), Miguel (2016) y Penna (2017). Los resultados muestran que el programa debe ser combatido por no tener apoyo legal y por violar los principios de la Constitución brasileña en la pluralidad de ideas y pensamientos.

Palabras clave: Género. Sexualidad. Educación. Escuela sin Partido.

\section{Introdução}

s temáticas sobre gênero e sexualidade têm sido objeto de debates e de dis-
cussões em diferentes enfoques, abordagens de pensamento e concepções,
evidenciando a importância de estudos sobre elas e de como as políticas educacionais têm tratado esses temas.

O presente artigo, fruto de pesquisa de mestrado que está em desenvolvimento na Universidade Federal de Pernambuco, objetiva analisar a importância das abordagens de gênero nas escolas e desconstruir os ataques do movimento/programa Escola Sem Partido (ESP) a essas temáticas.

Sobre as pautas destacadas pelo ESP a partir de 2014, elencamos a abordagem de temáticas voltadas a gênero e/ou sexualidade no currículo escolar brasileiro, polêmica que tem suas raízes no século passado, com maior tensão no período da ditadura civil-militar de 1964-1985, tendo em vista o grande controle institucional da atividade docente, com censura a diversos temas do currículo escolar (KATZ e MUTZ, 2017).

Após a promulgação da Constituição brasileira de 1988 (BRASIL, CFRB, 1988), que influenciou a elaboração da Lei de Diretrizes e Bases da Educação Nacional, nº 9.394, em 
1996 (BRASIL, LDB, 1996), o cenário educacional passou por um rearranjo. A discussão sobre o fortalecimento da democracia coloca a educação em um patamar prioritário, e dá primazia à educação em direitos humanos, mas, principalmente, à educação como direito humano, um bem social e, ao mesmo tempo, um direito subjetivo e basilar para execução de outros direitos.

Outro aspecto que influenciou as políticas educacionais foi o primeiro mandato de Lula, presidente da República eleito em 2002 e empossado em 2003, no qual houve um avanço nas ações e nos debates sobre temas relacionados a diversidade, gênero, orientação sexual, educação em direitos humanos, dentre outros.

Em 2004, o Governo Federal lançou o programa Brasil sem Homofobia, com o objetivo de combater a violência e o preconceito contra a população LGBT (composta por travestis, transexuais, gays, lésbicas, bissexuais e outros grupos) e de enfatizar a formação de educadores para tratar questões relacionadas a gênero e sexualidade. Nascia o projeto Escola sem Homofobia.

Por outro lado, nesse período verifica-se a constituição de movimentos contrários a essas pluralidades de temas, como o Escola sem Partido, que surge para criar oposição ao avanço das liberdades de expressão, pluralidades e diversidades de pensamento e concepções pedagógicas.

Hoje, a discussão sobre gênero e/ou sexualidade nas escolas tem sido alvo de diversas distorções, divulgações de notícias falsas e articulações de projetos de lei para proibir o tema e até mesmo a menção à palavra gênero no ambiente escolar. Essa proibição inclui os livros e materiais didáticos a serem utilizados sob pena de, conforme esses projetos, a escola ter que indenizar os pais por danos morais. Dessa maneira, a discussão a ser abordada neste trabalho, através de um recorte histórico e subsidiado por uma análise bibliográfica, é de suma importância para os rumos de uma educação democrática, plural, que respeita as diferenças e promove a inclusão.

\section{O que é o Escola Sem Partido?}

O Escola Sem Partido (ESP) surge como um movimento conservador, que se autodenomina movimento de doutrinação ideológica e de combate à ideologia "esquerdista" na escola. Idealizado por Miguel Nagib" , em 2004, influenciado por um movimento estadunidense - No Indoctrination (Nenhuma Doutrinação) - , que surgiu em 2002, com o objetivo de criar um fórum para divulgar os relatórios dos/as alunos/as sobre cursos e programas de faculdades e universidades que, em sua opinião, apresentassem preconceitos severos ou práticas equivalentes à doutrinação, esse movimento perdeu força e deixou de existir em 2010, e o site só pode ser visualizado através de plataformas de web archive.

Segundo o site do movimento, o ESP é 
Uma iniciativa conjunta de estudantes e pais preocupados com o grau de contaminação político-ideológica das escolas brasileiras, em todos os níveis: do ensino básico ao superior. A pretexto de transmitir aos alunos uma "visão crítica" da realidade, um exército organizado de militantes travestidos de professores prevalece-se da liberdade de cátedra e da cortina de segredo das salas de aula para impingir-lhes a sua própria visão de mundo (NAGIB, 2018).

Todavia, apesar de lançar algumas campanhas em canais e redes sociais como o Youtube, Facebook, blogs e outros, até o ano de 2013 o movimento não ganhou muitos adeptos ou grandes repercussões. Mas o fato de não gerar repercussões importou, também, na ausência de discussão dos teóricos da área. Éo que afirma Penna (2017, p. 35): “o discurso do Escola sem Partido não foi devidamente enfrentado, a meu ver, desde o momento em que ele surgiu, em 2004, justamente por parecer absurdo e sem fundamentos legais para aqueles que conhecem o debate educacional".

Em 2014, o cenário relacionado ao debate do Escola sem Partido teve um avanço quando o deputado estadual do Rio de Janeiro, Flávio Bolsonaro, procurou Miguel Nagib para transformar os ideais do Movimento Escola sem Partido (MESP) em um projeto de lei, com o intuito de alterar a Lei de Diretrizes e Bases da Educação Nacional e também alterar outros dispositivos, para inserir os seus princípios , estabelecendo os deveres do professor/a, no sentido de que ele/a deveria respeitar o direito dos pais/mães de que seus/ suas filhos/as recebam uma educação moral de acordo com suas convicções.

A partir desse marco de transformação do movimento em projeto de lei (PL), surgiu uma outra organização: o Programa Escola sem Partido (PESP) ${ }^{2}$ criado para disponibilizar os projetos de lei adaptados para as versões federal, estadual, municipal, decreto estadual e decreto municipal, de maneira que qualquer parlamentar - ou no caso dos decretos -, que qualquer chefe de Executivo pudesse ter acesso e, consequentemente, apresentá-lo na sua respectiva casa legislativa ou em outro espaço, conforme sua competência.

Porém, a propositura de projetos de lei/edição de decretos em nível estadual ou municipal sobre a mudança no currículo nacional vai de encontro ao previsto na Constituição, que estabelece ser de competência privativa da União dispor sobre as diretrizes e bases da educação nacional (BRASIL, CFRB/88, art. 22, XXIV).

Como forma de divulgar o MESP/PESP, a partir do ano de 2014 foram criados outros sites, páginas no Facebook, anúncios no Google etc. ou seja, a rede de divulgação social se fortaleceu, além de um contato com os deputados e vereadores, no intuito de garantir o PL.

Para Espinosa e Queiroz (2017, p. 49) falam sobre o Escola sem Partido:

Antes tida até como pueril, tamanha sua inconsistência teórica e jurídica, não se imaginava que a iniciativa tomaria a dimensão que tem hoje e que se espalharia para todo o Brasil, aproveitando uma forte onda conservadora e feroz, que se fortaleceu após as manifestações de 2013, passando pelas últimas e acirradíssimas eleições 
Diante da divulgação dos projetos de lei que versam sobre o ESP, o movimento ganha maior visibilidade e difusão em 2014. Conforme Cara (2016, p. 44), o próprio projeto declara ter três objetivos bem definidos: a "descontaminação e 'desmonopolização' política e ideológica das escolas"; 0 "respeito à integridade intelectual e moral dos estudantes"; e o "respeito ao direito dos pais de dar aos seus filhos uma educação moral que esteja de acordo com suas próprias convicções".

\section{Escola sem partido e a "ideologia de gênero"}

O ESP, de início, tinha por escopo a destituição do caráter educacional da escola e do papel do/a professor/a enquanto educador/a, sob a justificativa de evitar a doutrinação ideológica nas instituições de ensino, que, para o movimento, é realizada por esquerdistas.

No ambiente virtual do ESP há um espaço em que o movimento denomina de doutrina da doutrinação, e eles afirmam que, "por trás da ação aparentemente espontânea dos 'despertadores de consciência crítica', existe uma bem elaborada e difundida doutrina da doutrinação" (DOUTRINA... ,2019, documento eletrônico). Dentre os autores destacados pelos adeptos do movimento como doutrinadores, encontram-se referências a Karl Marx, Frei Betto, Paulo Freire e outros, distorcendo os conceitos básicos de suas obras.

Mas, quando estava para ser lançado o Caderno Escola sem Homofobia ${ }^{3}$, cuja finalidade é contribuir para a implementação e a efetivação de ações que promovam ambientes políticos e sociais favoráveis à garantia dos direitos humanos, da respeitabilidade das orientações sexuais e da identidade de gênero no âmbito escolar brasileiro, de maneira a estabelecer um contraponto à concepção didática heteronormativa ${ }^{4}$, conservadora e binária, bem como promover atividade inclusiva, em consonância com a promoção dos direitos humanos, da igualdade e do direito à diferença, um alarmismo buscou influenciar o direcionamento do debate sobre gênero nas escolas e as novas pautas a serem assumidas pelo ESP.

Em discussão na sessão da Câmara dos Deputados em 30 de novembro de 2010, na época em que era deputado federal, Jair Bolsonaro (posteriormente presidente da República, eleito em 2018) referiu-se a esse assunto como o "maior escândalo que tomou conhecimento até hoje", e pontuou que o kit era "um incentivo ao homossexualismo e à promiscuidade ${ }^{\prime \prime}$, o que gerou uma forte repressão dos/as parlamentares conservadores/as em relação ao Caderno. 
A partir desse episódio, que repercutiu a ponto de o material ser totalmente suspenso por Dilma Roussef ${ }^{6}$ em 2011, a bancada parlamentar fundamentalista religiosa passou a promover uma vigilância intensiva sobre as temáticas de educação sexual, gênero e escola, direitos homoafetivos e outros.

Nessa esteira, o debate sobre a perspectiva da moral e da concepção religiosa em relação aos conteúdos a serem adotados nas escolas passa a fazer parte dos fundamentos do ESP. Para Miguel (2016, p. 595):

\footnotetext{
O crescimento da importância do MESP no debate público ocorre quando seu projeto conflui para o de outra vertente da agenda conservadora: o combate à chamada "ideologia de gênero". Antes, a ideia de uma "Escola Sem Partido" focava sobretudo no temor da "doutrinação marxista", algo que estava presente desde o período da ditadura militar. O receio da discussão sobre os papéis de gênero cresceu com iniciativas para o combate à homofobia e ao sexismo nas escolas e foi encampado como bandeira prioritária pelos grupos religiosos conservadores. Ao fundi-lo à sua pauta original, o MESP transferiu a discussão para um terreno aparentemente "moral" (em contraposição a "político") e passou a enquadrá-la nos termos de uma disputa entre escolarização e autoridade da família sobre as crianças.
}

Após essa polêmica, desde 2015 surgiram dois elementos novos voltados à perseguição dos projetos relacionados a orientação sexual, gênero, diversidade e afins. O primeiro deles é a constituição oficial da Frente Parlamentar Evangélica do Congresso Nacional"; o segundo é a perseguição contra a abordagem de gênero, que passa a se dar através da via legislativa ativa, com propositura de Projetos de Lei.

Até então, foram apresentados 46 Projetos de Lei (PL) ${ }^{8}$, seja em nível federal, estadual ou municipal, que proibem a discussão da temática de gênero ou orientação sexual na escola e em materiais didáticos. O mais conhecido desses PL é o 1859/2015, que pretende acrescentar ao Art. $3^{\circ}$ da Lei de Diretrizes e Bases da Educação Nacional (LDB) o parágrafo único, determinando que:

Art. $3^{\circ}$

Parágrafo único: A educação não desenvolverá políticas de ensino, nem adotará currículo escolar, disciplinas obrigatórias, ou mesmo de forma complementar ou facultativa, que tendam a aplicar a ideologia de gênero, o termo "gênero" ou "orientação sexual" (BRASIL, 2015).

Além disso, o ESP passou a divulgar uma notificação extrajudicial, elaborada por Guilherme Schelb, Procurador Regional da República no Distrito Federal, com o auxílio de Nagib, a ser enviada para a direção das escolas e aos/às responsáveis pelos/as alunos/ as. A notificação prevê, entre outras coisas, que a escola que violar a formação moral e religiosa poderá ser acionada judicialmente por danos morais, sem prejuízo de ser acionado civilmente por danos à formação psicológica da criança. Além de trazer um tópico específico para as questões de gênero e sexualidade, sob o fundamento de que tais assuntos 
não devem ser abordados sem o expresso consentimento dos/as pais/mães/responsáveis em respeito à fragilidade psicológica dos/as alunos/as e sua condição de pessoa em desenvolvimento. A proibição se estende à forma ilustrativa ou informativa, por qualquer meio de comunicação ou orientação, através de vídeos, exposição verbal, música, livro de literatura ou material didático (SCHELB, 2016).

Para reforçar a campanha de ameaça a escolas, diretores/as e demais membros da equipe pedagógica, o movimento elaborou o cartaz seguinte:

\section{Ilustração 1: Campanha do ESP}

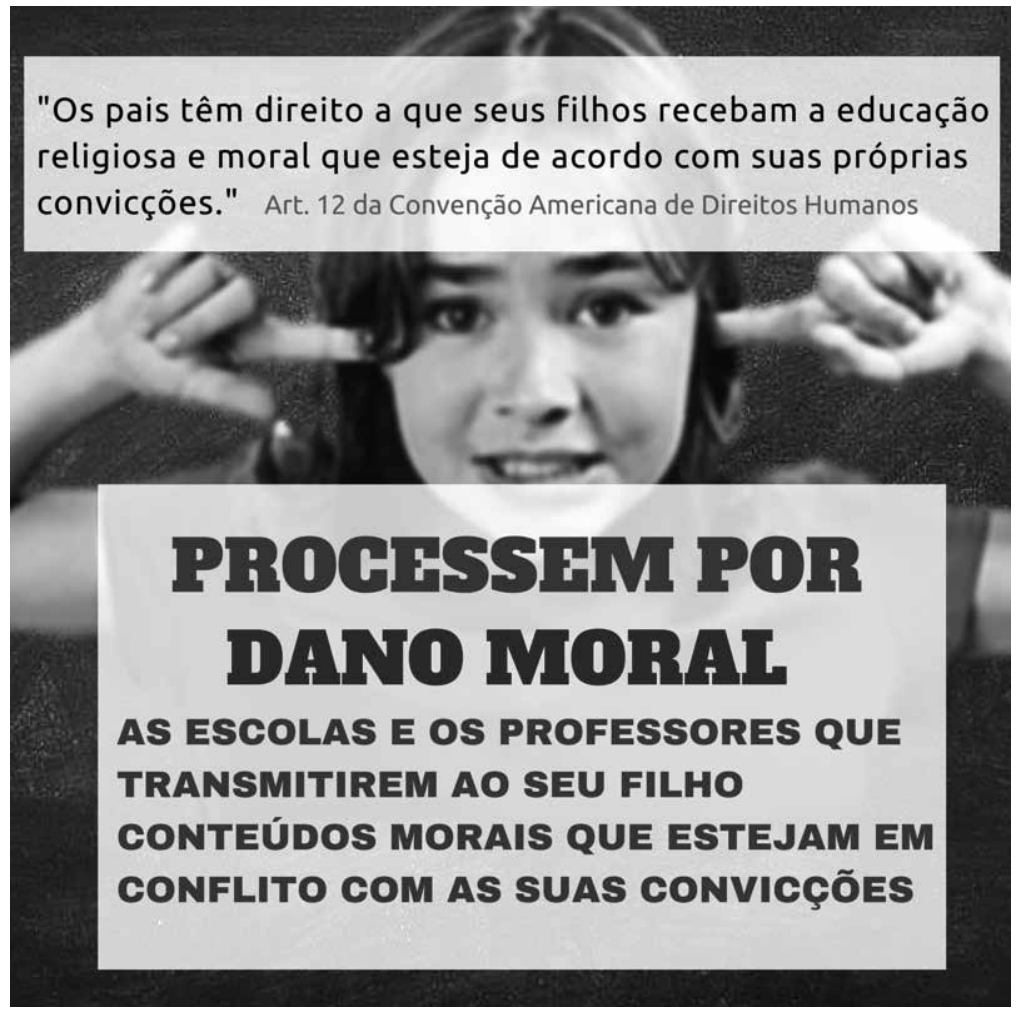

Fonte: http://deolhonolivrodidatico.blogspot.com/2016/02/familia-podera-processar-escola-e.html?m=1.

O termo "ideologia de gênero" fundamenta diversos documentos do ESP, a exemplo dos próprios Projetos de Lei e da notificação extrajudicial, além de estar presente em diversas charges e materiais dos sites a ele vinculados. Para os defensores da ideologia de gênero, isto significa "uma ideologia antifamília, uma tentativa de transformar os jovens em gays e lésbicas, um ataque à família" (PENNA, 2017, p. 45). Essa concepção representa uma falsa concepção, pois a discussão sobre gênero tem, a bem da verdade, o papel humano e social de desconstruir padrões de desigualdade, de machismo, de 
homofobia, e de trazer à tona representações reais de família homoafetiva, monoparental, coparental e outras.

Diante do avanço das perseguições perpetradas pelo ESP, diversas entidades de Direitos Humanos, da área educacional e da área religiosa, com apoio da Fundação Malala, do Ministério Público Federal e da Procuradoria Federal dos Direitos do Cidadão, lançaram o Manual de Defesa Contra a Censura nas Escolas.

O Manual faz um resgate dos diversos dispositivos legais que dão base para a abordagem de gênero, raça e sexualidade na educação, a exemplo da Constituição Brasileira (1988), que tem como um dos objetivos fundamentais, previstos no Art. 3º , item IV, promover o bem de todos, sem preconceitos de origem, raça, sexo, cor, idade e quaisquer outras formas de discriminação. O Manual resgata princípios constitucionais: da igualdade; da vedação à censura em atividades culturais; da laicidade do Estado; do pluralismo de ideias e concepções pedagógicas (também disposto na Lei de Diretrizes e Bases da Educação Nacional - LDB-1996, na Lei Maria da Penha-2006, que estabelece em seu Art. $8^{0}$ que a educação é estratégia fundamental para prevenir e coibir a violência doméstica e familiar contra as mulheres no País, e no Plano Nacional de Educação-2014, que em seu Art. $2^{\underline{0}}$ prevê a implementação de programas e políticas educacionais destinados a combater "todas as formas de discriminação" existentes nas escolas.

Dessa maneira, é patente que não há sustentação jurídica para os PL que pretendem abolir conteúdos de gênero e sexualidade no ambiente escolar ou, ainda, para as notificações extrajudiciais porventura apresentadas por pais/mães e responsáveis.

\section{A discussão de gênero e sexualidade nas escolas}

A discussão sobre a abordagem ou não de temas voltados a gênero e/ou sexualidade no âmbito escolar não é recente. De acordo com César (2009, p. 39), “as primeiras preocupações explícitas em relação à educação do sexo de crianças e jovens no Brasil tiveram lugar nos anos vinte e trinta do século XX".

Mas sua efetiva inserção na educação formal brasileira remonta à década de 60, conforme as considerações de Rosemberg analisadas por Altmann (2001, p. 579), ao evidenciar que nesse período algumas escolas públicas desenvolveram experiências de educação sexual. No entanto, elas deixaram de existir em 1970, após a Comissão Nacional de Moral e Civismo dar parecer contrário a um projeto de lei que propunha a inclusão obrigatória da educação sexual nos currículos escolares. Ainda, conforme Altmann, em 1976 a posição oficial brasileira afirmava que a família era a principal responsável pela educação sexual.

Britzman (1996, p. 78) analisa que:

Quando chega a ser tratado, o conhecimento de sala de aula sobre sexualidade é tipicamente sinônimo de reprodução heterossexual, embora até mesmo esse 
conhecimento seja banalizado. Além disso, a assim chamada informação técnica sobre reprodução sexual é altamente contestada porque a informação sobre o sexo é vista como a causa de aumento da atividade sexual.

As abordagens de gênero e sexualidade no ambiente escolar trazem consigo toda a amplitude da construção por trás dessas categorias. Entendemos a sexualidade de acordo com Louro (2000) e Foucault $(1988,1993)$ - um dispositivo histórico que se constitui a partir de múltiplos discursos sobre o sexo e gênero -, e, também, conforme Louro (1997), como uma categoria histórica, forjada nos arranjos sociais e constituinte da identidade das pessoas.

Ao refletir criticamente sobre a polêmica em torno dessas discussões, Furlani (2007) observa que as mesmas, quer sejam compreendidas como identidades culturais (constituidoras dos sujeitos) ou como temáticas (à educação sexual), sexo, sexualidade e gênero, podem ser vistas como monstros curriculares, e assim não podem fazer parte dos conteúdos que compõem o currículo.

Atualmente, temos dois documentos principais relacionados às abordagens de gênero e/ou sexualidade no ambiente escolar. O primeiro é sobre os Parâmetros Curriculares Nacionais $(\mathrm{PCN})^{9}$, que trazem, dentre outros temas transversais, a orientação sexual, ao disporem que:

Ao tratar do tema Orientação Sexual, busca-se considerar a sexualidade como algo inerente à vida e à saúde, que se expressa no ser humano, do nascimento até a morte [...] O objetivo deste documento é promover reflexões e discussões de técnicos, professores, equipes pedagógicas, bem como de pais e responsáveis, com a finalidade de sistematizar a ação pedagógica da escola no trato de questões da sexualidade (BRASIL, 1997, p. 287).

Além disso, os PCN informam que a orientação sexual engloba as relações de gênero, o respeito a si mesmo e ao outro e à diversidade de crenças, valores e expressões culturais em uma sociedade democrática e pluralista, prevendo que, ao abordar essa temática, os/as educadores/as

Devem transmitir, por sua conduta, a valorização da equidade entre os gêneros e a dignidade de cada um individualmente. Ao orientar todas as discussões, eles próprios respeitam a opinião de cada aluno e, ao mesmo tempo, garantem o respeito e a participação de todos, explicitando os preconceitos e trabalhando pela não discriminação das pessoas (BRASIL, 1997).

O segundo documento, mais recente, são as orientações técnicas de educação em sexualidade para o cenário brasileiro da Organização das Nações Unidas para a Educação, a Ciência e a Cultura (Unesco). Na apresentação da orientação da Unesco faz-se menção aos PCN, afirmando-se que: 
A primeira e mais importante iniciativa do governo federal para a inclusão da sexualidade na perspectiva do gênero como tema legítimo a ser discutido nas escolas foi a publicação, em 1997, dos Parâmetros Curriculares Nacionais (PCN) para o ensino fundamental, e dois anos depois, os PCN para o ensino médio. Esses dois documentos trazem como inovação a proposta de transversalização de temas considerados relevantes para a sociedade nos conteúdos escolares [...] Embora com um discurso ainda voltado à prevenção, os PCN lançaram as bases para que a educação em sexualidade - sobretudo na perspectiva das relações de gênero - fosse incluída como tema legítimo e importante no sistema educacional, levando subsídios a professores para que conteúdos específicos fossem incorporados de forma transversal aos currículos da educação básica de forma mais abrangente (UNESCO, 2013, p. 08).

É importante destacar que o entendimento da Unesco corrobora com a análise anterior destacada por Britzman, ao comentar que predomina uma concepção biologizante nas atividades escolares.

Apesar das grandes transformações sociais e comportamentais no campo da sexualidade e das relações de gênero observadas nas últimas décadas, a maioria das iniciativas escolares de educação em sexualidade, ainda hoje, concentra-se no discurso biologizante e científico do corpo, silenciando sobre questões importantes como o prazer, o desejo e a diversidade sexual (UNESCO, 2013, p. 07).

Apoiamos o pensamento de Britzman (2000, p. 108) no sentido de que o currículo que contempla conteúdos sobre a sexualidade deve estar mais próximo à dinâmica da sexualidade, devendo ir além dos limites do conhecimento disciplinado e do mecanismo defensivo do discurso escolar oficial. Ainda, conforme a autora, esse modelo de abordagem exige muito dos/as professores/as, pois estes/as devem estar dispostos/as a estudar a postura de suas escolas e ver como essa postura pode impedir ou tornar possíveis diálogos com outros/as professores/as e estudantes. Os/as professores/as precisam perguntar como o conteúdo pedagógico afeta a curiosidade do/a estudante e suas relações com os/as outros/as.

Nessa mesma linha, afirma Louro (1997, p. 64-65):

Dispostas/os a implodir a ideia de um binarismo rígido nas relações de gênero, tere-
mos de ser capazes de um olhar mais aberto, de uma problematização mais ampla (e
também mais complexa), uma problematização que terá de lidar, necessariamente,
com as múltiplas e complicadas combinaçoses de gênero, sexualidade, classe, raça,
etnia. Se essas dimensões estão presentes em todos os arranjos escolares, se estamos
nós próprias/os envolvidas/os nesses arranjos, não há como negar que essa é uma
tarefa difícil. Trata-se de pôr em questão relações de poder que compartilhamos, rela-
ções nas quais estamos enredadas/os e que, portanto, também nos dizem respeito.

Nesses embates político-ideológicos que a educação brasileira tem vivenciado, merece destaque a decisão do ministro do Supremo Tribunal Federal (STF), Luís Roberto Barroso, que suspendeu, em 2017, por meio da Ação de Descumprimento de Preceito Fundamental (ADPF) nº 461, os efeitos de uma lei do município Paranaguá-PR. O art. 3º, item 
X, parte final, dessa Lei 3.468 de 23 de junho de 2015, que dispunha sobre a aprovação do Plano Municipal de Educação de Paranaguá, previa como uma das diretrizes a "promoção dos princípios do respeito aos direitos humanos, à diversidade e à sustentabilidade socioambiental, sendo vedada entretanto a adoção de políticas de ensino que tendam a aplicar a ideologia de gênero, o termo 'gênero' ou 'orientação sexual'" (BRASIL, 2017, grifos do autor).

O ministro Barroso afirmou, ainda, que, obstar políticas de ensino que tratem de gênero, orientação sexual ou que utilizem tais expressões significa impedir que as escolas abordem esses assuntos, esclareçam as diferenças e orientem seus alunos, pois a diversidade de identidades de gênero e de orientação sexual é um dado presente na sociedade. Os alunos são seres em formação e a educação sobre o assunto pode ser essencial para a auto compreensão, além de contribuir para assegurar sua própria liberdade, sua autonomia, bem como para os proteger contra a discriminação (BRASIL, 2017).

Entendemos que a importância das abordagens de gênero e/ou sexualidade nas escolas se dá através dessa dinâmica de fugir do padrão biologizante e científico e, consequentemente, permitir o debate, a troca e o efetivo processo de ensino-aprendizagem, de modo a promover o respeito, a diversidade, a auto compreensão e a pluralidade desses processos, sem imposição de um padrão cultural naturalizado.

\section{Considerações finais}

Os temas transversais dos PCN e as orientações técnicas da Unesco têm representado grande avanço na mudança do discurso sobre como as temáticas de gênero e sexualidade e devem ser abordadas no espaço educacional.

É importante que as instituições de ensino adotem as diretrizes dispostas nos PCN e nas orientações técnicas da Unesco, priorizando a capacitação dos/as profissionais da educação nessas temáticas, dando eficácia aos documentos que asseguram a pluralidade e a não discriminação, e fortalecendo práticas pedagógicas em um contexto dinâmico, com diálogos para além dos limites conservadores e morais.

As ações levantadas pelo "Escola sem Partido", através da proliferação de propostas legislativas ou de notificações extrajudiciais que tolhem a liberdade de aprender e ensinar e impedem o debate sobre gênero e sexualidade, devem ser combatidas para que não tenhamos nenhum retrocesso no que se refere à política educacional voltada à promoção desses temas.

O Manual de Defesa Contra a Censura nas Escolas é um guia que dá sustentáculo para a afirmação dos princípios éticos, políticos e jurídicos, que dão suporte à educação brasileira em suas diferentes etapas e modalidades. Serve de instrumento para o debate público e contribui para o enfrentamento de um conflito social gerado pela manipulação das ideias. 


\section{A discussão e o aprofundamento desses conteúdos nos espaços escolares são} importantes para a educação, como forma de desconstruir os ataques desonestos do movimento/programa ESP, inclusive pela ausência de discussão teórica sobre o ESP, que não foi devidamente enfrentado pelos/as educadores/as.

Por fim, compreendemos que é papel da escola trabalhar os conteúdos curriculares nas suas diferentes dimensões - histórico/cultural, política, social e filosófica -, de modo a entender que medidas cerceiam o processo de ensino-aprendizagem e ferem princípios educacionais previstos na CFRB/88 e na LDB/96.

\section{Recebido em: 14/02/2019, Reapresentado em: 19/07/2019 e Aprovado em: 06/08/2019}

\section{Notas}

1 Procurador de Justiça do Estado de São Paulo desde 1985, criador e atual coordenador do Movimento Escola Sem Partido.

2 No site do programa, destaca-se essa diferenciação: “O Escola sem Partido se divide em duas vertentes muito bem definidas, uma, que trabalha à luz do Projeto Escola sem Partido, outra, uma associação informal de pais, alunos e conselheiros preocupados com o grau de contaminação político-ideológica das escolas brasileiras, em todos os níveis: do ensino básico ao superior". Disponível em: https://www.programaescolasempartido.org/ movimento. Acesso: 30 jul. 2018.

3 O Caderno Brasil sem Homofobia era um projeto aliado ao Programa Brasil sem Homofobia, que, dentre suas ações, previa a atuação no direito à educação para promover valores de respeito à paz e à não discriminação por orientação sexual.

4 Para Warner, apud Britzman (1996, p. 79), "heteronormatividade é a obsessão com a sexualidade normalizante, através de discursos que descrevem a situação homossexual como desviante".

5 A fala completa do parlamentar pode ser visualizada em: https://www.youtube.com/watch?v=ONfPCxKdGT4. Após as incitações feitas, a bancada evangélica se apropriou das discussões e passou a se referir ao material como "kit gay". Outrossim, conforme Carrano (2013), em 1990, a Organização Mundial da Saúde retirou a homossexualidade da lista de doenças mentais do Código Internacional de Doenças. A decisão também eliminou o uso do sufixo 'ismo', desvinculando a orientação sexual da ideia de enfermidade.

6 Presidenta da República à época (1ํㅡandato - 2009-2012).

7 Requerimento 3424, em 21 de outubro de 2015. Disponível em: https://www.camara.leg.br/internet/deputado/Frente_Parlamentar/53658-integra.pdf. Acesso em 11 de jul. 2019.

8 O levantamento inicial foi realizado por Moura (2016), que elaborou o quadro panorama do Escola sem Partido no Brasil. O quadro versa sobre Projetos de Lei que tramitam com a temática de proibição de gênero ou que estabelecem o Programa Escola sem Partido. Para a construção do presente trabalho, levou-se em conta apenas os PL relacionados a gênero. A tabela está disponível em: https://professorescontraoescolasempartido.wordpress.com/vigiando-os-projetos-de-lei/ e teve sua última atualização em 08/01/2018.

9 Conforme Altmann (2001, p. 579), "os PCNs pretendem ser um referencial fomentador da reflexão sobre os currículos escolares, uma proposta aberta e flexível, que pode ou não ser utilizada pelas escolas na elaboração de suas propostas curriculares". 


\section{Referências}

ALTMANN, Helena. Orientação sexual nos parâmetros curriculares nacionais. Revista Estudos Feministas, v. 2, 2001.

BRASIL. Supremo Tribunal Federal. Arguição De Descumprimento De Preceito Fundamental $\mathbf{n}^{\mathbf{0}}$ 461. Direito à educação. Medida cautelar em arguição de descumprimento de preceito fundamental. Lei municipal que veda o ensino sobre gênero e orientação sexual, bem como a utilização desses termos nas escolas. Brasília, 16 de junho de 2017. Disponível em: http://portal.stf.jus.br/processos/ downloadPeca.asp?id=312038140\&ext=.pdf. Acesso: 08 jul. 2019.

Caderno Escola Sem Homofobia. Disponível em: http://www.acaoeducativa.org.br/fdh/ wp-content/uploads/2015/11/kit-gay-escola-sem-homofobia-mec1.pdf. Acesso: 17 jul. 2019.

Constituição da República Federativa do Brasil (1988). Promulgada em 05 de outubro de 1988. Disponível em: http://www.planalto.gov.br/ccivil_03/constituicao/ constituicaocompilado. htm. Acesso em: 20 ago. 2018.

. Lei no 9.394, de 20 de dezembro de 1996. Estabelece as Diretrizes e Bases da Educação Nacional. Disponível em: http://www.planalto.gov.br/CCIVIL_03/Leis/ L9394.htm. Acesso em: 10 ago. 2018.

. Câmara dos Deputados. Projeto de Lei 1859, de 2015c. Acrescenta Parágrafo único ao artigo $3^{\circ}$ da Lei 9.394/96 (Lei de Diretrizes e Bases da Educação). Brasília-DF, apresentação em 10 de junho de 2015. Disponível em: https://www.camara.gov.br/proposicoesWeb/fichadetramitacao?idProposic $\mathrm{ao}=1302894$. Acesso em: 20 de jun. 2018.

. Parâmetros Curriculares Nacionais/ Ensino Fundamental: Orientação sexual. Brasília: Ministério da Educação, 1997.

Plano Nacional de Educação em Direitos Humanos. Brasília, DF: SECRETARIA Especial dos Direitos Humanos (PR), Ministério da Educação, Ministério da Justiça, UNESCO, 2003.

CONSELHO Nacional de Combate à Discriminação. Brasil Sem Homofobia: Programa de combate à violência e à discriminação contra GLTB e promoção da cidadania homossexual. Brasília: Ministério da Saúde, 2004.

BRITZMAN, Déborah. Curiosidade, sexualidade e currículo. In: LOURO, Guacira Lopes (org). O corpo educado: pedagogias da sexualidade. Tradução dos artigos: Tomaz Tadeu da Silva. Belo Horizonte: Autêntica, 2000.

O que é essa coisa chamada amor: identidade homossexual, educação e currículo. In Educação \& Realidade, v. 21 (1), jan./jun, 1996.

CÉSAR, Maria Rita de Assis. Gênero, sexualidade e educação: notas para uma "Epistemologia”. Educar em Revista, Curitiba, n. 35, p. 37-51, 2009.

CARA, Daniel. O Programa “Escola Sem Partido" quer uma escola sem educação. In: Ação Educativa Assessoria, Pesquisa e Informação (Org.). A ideologia do movimento Escola Sem Partido: 20 autores desmontam o discurso. São Paulo: Ação Educativa, 2016.

CARRANO, Paulo. Há 23 anos a homossexualidade deixava de ser considerada pela OMS uma doença mental. Disponível em: http://www.emdialogo.uff.br/content/ha-23-anos-homossexualidadedeixava-de-ser-considerada-pela-oms-uma-doenca-mental. Acesso: 05 jul. 2018. 
DOUTRINA DA DOUTRINAÇÃO. Escola Sem Partido. Disponível em: http://www. escolasempartido.org/doutrina-da-doutrinacao. Acesso: 07 jul. 2019.

ESPINOSA, Betty R. Solano; QUEIROZ, Felipe B. Campanuci. Breve análise sobre as redes do Escola sem Partido. In: FRIGOTTO, Gaudêncio (Org.) Escola "sem" partido: esfinge que ameaça a educação e a sociedade brasileira. Rio de Janeiro: UERJ, LPP, 2017.

Família poderá processar escola e professor pelo ensino da ideologia de gênero: modelo de notificação extrajudicial (2016). Disponível em: http://deolhonolivrodidatico.blogspot.com/ 2016/02/familiapodera-processar-escola-e.html?m=1. Acesso: 05 ago. 2018.

FOUCAULT, Michel. Microfísica do poder. 11ª ed. Rio de Janeiro: Graal, 1993.

História da sexualidade. Volume 1: A vontade de saber. Rio de Janeiro: Graal, 1988.

FURLANI, Jimena. Sexos, sexualidades e gêneros: monstruosidades no currículo da Educação Sexual. Educação em Revista, UFMG: Belo Horizonte, n.46, pp.269-285, 2007.

JAPIASSÚ, Hilton; MARCONDES, Danilo. Dicionário Básico de Filosofia. 3a ed. Rio de Janeiro: Jorge Zahar, 2001.

KATZ, Elvis Patrik; MUTZ, Andresa Silva da Costa. Escola Sem Partido - produção de sentidos e disputas em torno do papel da escola pública no Brasil. Educação Temática Digital, Campinas, v.19 n. esp., p. 184-205 jan./mar. 2017

LOURO, Guacira Lopes. Pedagogias da Sexualidade. In: LOURO, Guacira Lopes (org.). O corpo educado: pedagogias da sexualidade. Belo Horizonte: Autêntica, 2000.

Gênero, sexualidade e educação: Uma perspectiva pós-estruturalista. Petrópolis, RJ. Vozes, 1997.

MANUAL DE DEFESA CONTRA A CENSURA NAS ESCOLAS. Disponível em: http://www. manualdedefesadasescolas.org/manualdedefesa.pdf. Acesso: 10 jul. 2019.

MIGUEL, Luís Felipe. Da "doutrinação marxista" à "ideologia de gênero" - Escola Sem Partido e as leis da mordaça no parlamento brasileiro. Direito e Práxis Revista, Rio de Janeiro, v. 07, n. 15, p. 590-621, ago. 2016.

MOURA, Fernanda Pereira de. "Escola Sem Partido": Relações entre Estado, Educação e Religião e os impactos no Ensino de História. 2016, 188 f. Dissertação (Mestrado) Programa de Pós-Graduação em Ensino de História, Instituto de História, Universidade Federal do Rio de Janeiro - UFRJ, Rio de Janeiro.

NAGIB, Miguel. Quem somos. Disponível em: http://www.escolasempartido.org/quem-somos. Acesso: 05 ago. 2018.

PENNA, Fernando de Araújo. O Escola sem Partido como chave de leitura do fenômeno educacional. In: FRIGOTTO, Gaudêncio (Org.) Escola "sem" partido: esfinge que ameaça a educação e a sociedade brasileira. Rio de Janeiro: UERJ, LPP, 2017.

SCHELB, Guilherme. Modelo de notificação extrajudicial de escolas. Disponível em: https:// infanciaefamilia.com.br/modelo-de-notificacao-extrajudicial-de-escolas/. Acesso: 05 ago. 2018.

UNESCO. Orientações técnicas de educação em sexualidade para o cenário brasileiro: tópicos e objetivos de aprendizagem. Brasília, 2013. 